\title{
Why Play? \\ Examining the Roles of Play in ICTD
}

\author{
Pedro Ferreira \\ Mobile Life@KTH \\ Stockholm, Sweden \\ i@pedropaf.com
}

\begin{abstract}
The role of technology in socio-economic development is at the heart of ICTD (ICTs for development). Yet, as with much Human Centered technology research, playful interactions with technology are predominantly framed around their instrumental roles, such as education, rather than their intrinsic value. This obscures playful activities and undermines play as a basic freedom. Within ICTD an apparent conflict is reinforced, opposing socio-economic goals with play, often dismissed as trivial or unaffordable. Recently a slow emergence of studies around play has led us to propose a framing of it as a capability, according to Amartya Sen, recognizing and examining its instrumental, constructive, and constitutive roles. We discuss how play unleashes a more honest and fair approach within ICTD, but most importantly, we argue how it is essentially a basic human need, not antithetical to others. We propose ways for the recognition and legitimization of the play activity in ICTD.
\end{abstract}

\section{Author Keywords}

Play; ICTD; ICT4D; capabilities; freedom; games; entertainment

\section{ACM Classification Keywords}

H.5.m. Information interfaces and presentation (e.g., HCI): Miscellaneous.

\section{INTRODUCTION}

Whenever we talk about ICT use, it is hard not to think about its gaming and entertainment potential. It is certainly self-evident that these aspects have been a major driver behind the success and mass adoption of ICTs worldwide (see for instance Sey and Ortoleva for a short review [75]). While apparently evident, we fail to see the acknowledgment of those activities as ends in themselves, intrinsically valuable and even as basic freedoms we enjoy as humans. Recognizing playfulness as it unfolds in everyday life becomes all the more challenging in Information and Com-

Copyright $(2015$ is held by the author(s). Publication rights licensed to Aarhus University and ACM

5th Decennial Aarhus Conference on Critical Alternatives August $17-21,2015$, Aarhus Denmark

DOI: http://dx.doi.org/10.7146/aahcc.v1i1.21264 munication Technologies for Development (ICTD or ICT4D). The focus on the urgency to satisfy a pre-defined set of socio-economic needs relegates play as something poor people cannot afford to engage with. Generally speaking, there has not been a lack of excitement around the advent of the information age. ICTs were, early on, framed around their potential to improve and optimize business processes and efficiency [9, 27, 48]. In the late 80's, Nobel Laureate Robert Solow challenged this enthusiasm with a famous quip: "You can see the computer age everywhere but in the productivity statistics" [78], echoing the concern that such explanations were insufficient to account for the overwhelming success and excitement around ICTs. While history has certainly justified the role of ICTs in promoting the advancement of a variety of socio-economic goals, this remains a narrow and insufficient way to account for and understand the mass personal adoption of these technologies. Within ICTD, this type of focus, is especially predominant and fails to account for some of the main aspects of technology use: i.e. entertainment, leisure or games.

Today, digital interactions, particularly in the form of smartphones, pervade Western and developing worlds alike. Mobile subscriptions have nearly matched the earth's population, and 3 million people now have access to internet [80]. And while leisure and ludic interactions with technology are prominent, they lack the acceptance within academic work around technology use. It is now roughly 10 years since Bødker described third-wave HCI (Human Computer Interaction) in which understandings of technology must move beyond the office and into everyday life [8]. It is also close to 10 years since Gaver first published his work on ludic engagement [28], making play a legitimate goal in and of itself, pointing to the richness that play around technology brings into people's lives. ICTD, in its more consumer focused facet, understanding and harnessing the potential of personal ICTs such as mobile phones, in what Heeks named ICT4D 2.0 [33], is also bordering on 10 years. This is the right time to review and understand how play has been treated within the community, and point to future directions for a more honest understanding of ICTD work, as well as the importance of recognizing individual and local agency through play. We need an understanding of digital technologies where play, gaming and entertainment are recognized legitimate activities, resisting the 
temptation of marginalizing these forms of interaction, or legitimizing them only insofar they permit the achievement of other, external, goals. This is key for understanding the importance and desirability of digital technologies in people's lives.

We begin with a broad understanding of play, as an academic concern, so as to derive a common, everyday understanding of the term to be used in analyzing its role in ICTD work. We then build on Nussbaum's notion of play as a basic capability [59] framing it under Sen's notions of instrumental, constructive and constitutive roles [71] and drawing implications for understanding previous work in ICTD. Our aim is to acknowledge play as an activity people have a reason to value in itself, not contradictory with other ICTD goals. We discuss ways to reframe our thinking about play in ICTD, away from more paternalistic discourses, to repurpose the play concept as a valuable resource.

\section{WHAT DO WE MEAN WHEN WE TALK ABOUT PLAY?}

Play is an elusive concept, it is discussed from many different perspectives, and, as pointed out by sociologist Thomas Henricks, it suffers from the cantoning of disciplines around the concept [35]. Once more prominent within the domain of psychology and highly influential child development studies by Jean Piaget [61], it has captivated interest from a variety of disciplines, such as anthropology [30, 49] or sociology [35]. Henricks argues for revisiting the classical authors, less constrained by the tranches of academia, in order to get a more unified understanding of play. We proceed to a brief overview of play, to help us build an understanding, useful for thinking of play within ICTD.

\section{The origins and importance of play}

Dutch Cultural Historian Johann Huizinga, in his seminal work Homo Ludens [40], provides us with the first academic text focused exclusively on play. For Huizinga, play is not an element within culture, but rather a foundational aspect that precedes culture itself. In his words (the bold is ours for emphasis on foundational aspects):

"Summing up the formal characteristic of play, we might call it a free activity standing quite consciously outside 'ordinary' life as being 'not serious' but at the same time absorbing the player intensely and utterly. It is an activity connected with no material interest, and no profit can be gained by it. It proceeds within its own proper boundaries of time and space according to fixed rules and in an orderly manner." [40]

Huizinga lays down the foundations for what most have picked on to discuss play, namely: (1) that it is free, bounded by no other material interest than the play itself; (2) that it is explicitly non-serious, standing outside ordinary life; (3) that it absorbs the player; and (4) that it has boundaries in time, space as well as rules. For Huizinga, and for most authors who have discussed the concept, as we will see, these are important concepts that demarcate play:
"Inside the play-ground an absolute and peculiar order reigns. Here we come across another, very positive feature of play: it creates order, is order. Into an imperfect world and into the confusion of life it brings a temporary, a limited perfection. " [40] (p.10)

For Huizinga, play is one of the most important and foundational activities humans (and animals) engage in. When Huizinga writes "not serious" it is to place it in contrast with the many requirements of everyday life. Play is of primary importance, particularly through its "limited perfection" and "order", which stands in stark contrast with other everyday notions of play that emphasize its triviality.

More recent scholars, like Brian Sutton-Smith, have emphasized the importance of play as an indispensable mechanism for survival [82]. And in their in-depth analysis of the different types of play existing in humans and animals alike, Brown \& Vaughn focus on the importance of play for a normal development of the brain, and a transformative force, capable of improving people's lives dramatically and vital for survival: "the opposite of play is not work, it is depression" [11].

One of the concepts more closely tied to play is that of games. Huizinga in fact refers to play, mainly (but not only) as an action one does with games. If play is a challenging concept to unpack, game is certainly not easier. Roger Caillois categorizes play within four different types [13], building on the Greek terms: (1) Agon, referring to games of a competitive nature, (2) Alea, pertaining to games of chance, such as casino games, (3) Mimesis, referring to role playing and (4) Ilinx, which encompass aspects of extreme sports that provide adrenaline rushes and even taking hallucinogenic substances or riding rollercoasters. Games are one of the most extensively studied forms of play, both in academia in general $[13,40,81]$, as well as around technology more specifically $[42,52,69,83]$. We discuss games throughout, in the common, everyday understanding of the term, encompassing all these different forms. But it is worth emphasizing that not all play comes in the form of games.

\section{Free play}

For artist Allan Kaprow, the distinction between playing and gaming is actually an important one:

"This critical difference between gaming and playing cannot be ignored. Both involve free fantasy and apparent spontaneity, both may have clear structures, both may (but needn't) require special skills that enhance the playing. Play, however, offers satisfaction, not in some stated practical outcome, some immediate accomplishment, but rather in continuous participation as its own end. Taking sides, victory, and defeat, all irrelevant in play, are the chief requisites of game. In play one is carefree; in a game one is anxious about winning" [44]

For Kaprow, even goals within the game itself (what Suits calls prelusory goals [81]), such as winning the game, a 
goal, for Huizinga already separated from everyday life defined only through the willingness of players to accept those goals for the sake of the game playing itself. Kaprow is interested in liberating the player further, and is only willing to consider play in the form of free play, an exploration free from worries and goals whether internal or external to itself. It is not just an escape from ordinary life, but it is an escape from other forms of stress or anxiety.

Most work regarding the importance of free play comes from psychology, and more specifically child psychology. This interest originates more prominently in Jean Piaget's early work on children's stages of development and the role of play as the motor through which children explore and derive their understanding of the world, as well as an important tool in education [61]. While Piaget's focus was centered around child play, and not adult play for instance, his concept of play remains close to the one of Kaprow's ideas of liberation through freer exploration and engagement with the world, and as a fundamental mechanism for development and learning [31].

\section{Absorption, flow, autotelic and personal engagements}

An important aspect for understanding the play experience, and the desire to partake in it, is the often-mentioned absorption of the player, since all the way back to Huizinga's characterization [40]. This aspect has again been more extensively studied within psychology, namely in reversal theory. Reversal theory tries to understand motivation and draw distinctions between the concept of paratelic, denoting the kinds of activities which are pursued as means to an end, and autotelic, denoting those engaged in for the enjoyment in the process itself [2]. Autotelic engagements denote moments in which people are absorbed in activities, escaping worldly, everyday realities. This has been discussed by Csikszentmihalyi's through his influential work on flow [17], denoting that state in which one is absorbed into an intrinsically rewarding activity, pursuing it intensely for its own sake. While Csikszentmihalyi describes it as a personal feature, it is often taken, and easily translatable as a feature of the activities themselves:

"An autotelic person needs few material possessions and little entertainment, comfort, power, or fame because so much of what he or she does is already rewarding. Because such persons experience flow in work, in family life, when interacting with people, when eating, even when alone with nothing to do, they are less dependent on the external rewards that keep others motivated to go on with a life composed of routines. They are more autonomous and independent because they cannot be as easily manipulated with threats or rewards from the outside. At the same time, they are more involved with everything around them because they are fully immersed in the current of life." [17].

It is also building on these notions of intrinsically valued engagements, that we build our understanding of play. These may manifest themselves in very distinct ways than gaming, such as interpersonal communication and social networking. Studies such as Wyche's around Facebook use in Kenya [86], amongst others [19, 22, 39] show the importance people ascribe to these uses, which should not be necessarily striking as they are otherwise prevalent amongst users in the Western world as well.

\section{How and why we use play}

While there is value in these categorizations and discussions, we will use play as encompassing most of the categories above. What is important here is an understanding of activities, which share some, or all of the following aspects:

- They are engaged in freely, meaning its something people value and engage in willingly, outside of external pressures to do so.

- They stand outside of ordinary life, in that they provide escape from the everyday routines and hardships. This is related to them being bounded in space and time, implying a demarcation from other activities, even when these are not always evident.

- $\quad$ They are pursued for their own sake, meaning that they possess an autotelic or non-instrumental value, rather than serving an external purpose. This is often coupled with a state of flow, or intense absorption.

These do not represent a strict set of necessary conditions to classify something as play, but rather guidelines to understand activities regularly placed under play, such as games, entertainment, fun or leisure. We will use these rather loosely, and at times include activities which may seem contrary to some of these principles, but which should still reasonably be understood as essentially playful. Other ways of classifying the same phenomena could be under unserious or non-instrumental, but using either of these, and other terminologies, ultimately undermines the focus of this work. For instance talking about these activities as noninstrumental implies a degree of uselessness, contrary to our main argument that these are the basis for leading a good life. Equally, to call them unserious would be, deny the serious of play itself, and its constitutive role as an essential freedom, as philosopher Kurt Riezler expressed:

"Man's playing is his greatest victory over his dependence and finiteness [...]. He can also play, i.e., detach himself from things and their demands and replace the world of given conditions with a playworld of his own mood, set himself rules and goals and thus defy the world of blind necessities, meaningless things, and stupid demands. Religious rites, festivities, social codes, language, music, arteven science - all contain at least an element of play. You can almost say that culture is play. In a self-made order of rules man enjoys his activities as the maker and master of his own means and ends. Take art. Man, liberated from what you call the real world or ordinary life, plays with a world of rhythms, sounds, words, colors, lines, enjoying the 
triumph of his freedom. This is his seriousness. There is no 'merely'." [67]

\section{Play as capability}

Capability theory is a welfare economics concept introduced by Nobel Laureate Amartya Sen, and it stands at the root of arguably the most widely used measure of achievement of human needs, the Human Development Index (HDI) [1]. The HDI is closely tied to the Millenium Development Goals (MDG) [62], which constitute the basis established by the United Nations (UN) to guide development work in general, and as a consequence, ICTD efforts. The development of capabilities is, according to Sen, based on the idea that development should focus on enhancing people's abilities to choose the lives they have reasons to value.

Martha Nussbaum, who worked with Sen in the development of capability theory, and is arguably the main authority on the subject, has written briefly about play as a capability. Nussbaum briefly describes play as "Being able to laugh, to play, to enjoy recreational activities." [58] Nussbaum however, has not published as extensively on the topic of play as capability, with some notable exceptions discussing how some, in particular women, may lack opportunities for play and some of the consequences:

"Often burdened with the "double day" of taxing employment and full responsibility for housework and child care, they [women] lack opportunities for play and the cultivation of their imaginative and cognitive faculties. All these factors take their toll on emotional well-being: women have fewer opportunities than men to live free from fear and to enjoy rewarding types of love-especially when, as is often the case, they are married without choice in childhood and have no recourse from a bad marriage." [57]

It is under this frame that we understand the importance of play, not as a superfluous activity, but as an essential capability towards living a good life; engaging in and exerting the freedoms that one has reasons to value. Building on Sen's terminology, we will look at the role of play as instrumental, i.e. as a means-to-an-end, its constructive role, i.e. in building a consistent and honest interaction between researchers, designers and users. Finally, we arrive at our main goal here: how we can understand its constitutive role, i.e. as an unapologetic end-in-itself.

\section{PLAY AS INSTRUMENTAL}

Play, and games in particular, have been discussed in ITCD mainly given their instrumental roles. We will now look at the work done in this area, which represents the main contributions to the understanding of play within ICTD, drawing on examples from education, job searching and health.

\section{Within education}

Perhaps the most famous and widely covered experiment with technology and education in development is Sugata Mitra's Hole in the Wall (HiW) experiment. This experi- ment started with the carving of a literal Hole in The Wall between Mitra's workplace, NIIT and an adjoining slum in New Delhi, known as Kalkaji [53], where a computer was put to use freely. This experiment proved to be a widely mediatized success story of free learning and playing by the children in the slum, who with only "minimal guidance" derived multiple useful interactions from the computer, achieving a number of measurable educational outcomes $[53,54]$. This has then been scaled to hundreds locations and has reached thousands of children in India and Africa [37]. Part of the project's success is the emphasis on how entertaining and motivating content contributed to the successful educational experiment.

One of the most notable efforts in this area since then has been led by Matthew Kam in designing for, and studying, the impact of digital gaming, particularly on the mobile, in English language education [42]. Long term trials have reported significant successes [43]. Studies in ICTD have praised the potential for games and leisurely activities in supporting educational goals, from literacy goals, to mathematics [5], with games being early on lauded as a good educational tool through its engaging function [29]. Play and games for education are arguably the most represented within ICTD understandings of play and games, and fall under the rubric of serious games [52] which is also an important field within technology studies at large.

\section{Job training}

Education is not the only field in which games and entertainment can have a positive, instrumental, role. Polly is a telephone based voice manipulation and forwarding system deployed in Pakistan by Raza et. al. [66]. It has had measurable impact during its large scale and long-term deployment with nearly half a million interactions and 85.000 registered users at the time, and showing considerable tendency in growth. The authors used entertainment to draw people to the service where other development services could be provided. They wanted to ask the questions:

“(1) Is it possible to virally spread awareness of, and train people in, speech-based services, in a largely low-literate population, using entertainment as a motivation? (2) Is it possible to leverage the power of entertainment to reach a large number of people with other speech-based services?" [65]

Their evaluation turned out largely positive with the high rates of adoption and job creation, as well as plentiful evidence that users were extracting entertainment and leisurely value from the service, beyond the development offer [65].

\section{Non-prescribed uses}

Within health applications in ICTD, Schwartz and colleagues worked with the deployment of mobile devices to health workers in India. These devices were intended for purposes of collecting health data in eight different projects [70]. They note how workers also used these devices for 
more personal goals, beyond the intentions of deployment, calling these 'non-prescribed uses' [70]. The authors reflect on how explicitly allowing for these non-prescribed uses, helps to have a more honest engagement with the workers themselves. These did not feel the need to hide such behaviors, and it even worked as an extra motivation to participate in the project itself.

In this example, we extend the notion of play to include much of the personal use of technologies more broadly, particularly in a work context. It is about respecting people's desire to use these technological possibilities for their own purposes, the freedom to use them for stepping out of everyday work tasks, creating a playground beyond the instrumental value of the tasks they were given the devices to accomplish. Rather than fighting these uses, the project leaders figured that simply allowing for them created a better engagement with the health workers, leading to increased efficiency for the overall project.

We have seen how games and entertainment can bring about positive benefits as educational strategies. We have seen how they can help in engaging people with technological interventions, as well as providing motivation for users participating in other projects, by not restricting some of the non-prescribed uses. While we find this type of instrumentalization of play a rather narrow view on the phenomena, it is nonetheless one that should be respected, since it helps steer away from a vision where play may harm or detract from development goals. Echoing Sen's discussion on democracy and development not being contradictory goals (as is sometimes assumed) and the idea of the "presumed existence of a deep conflict [...] [when] studies show how both are important and have no conflict" [71] (p.149-150). Like Sen, we discuss this to help alleviate some of the concerns which emerge around play, and which we will see in more detail. But this should not detract from the importance of play in other ways, beyond and regardless of whether it achieves other goals or not.

\section{PLAY AS CONSTRUCTIVE}

One aspect, which is not often mentioned when discussing, play, but with important consequences, is what Sen describes as (specifically referring to democratic rights) the "constructive role in the genesis of values and priorities" [71]. That is the right for people and communities to openly discuss and reorganize what values are important, and what goals to prioritize. This needs to be a constant, deliberative process that involving the affected, or targeted, communities. As Sen puts it:

"The need to discuss the valuation of diverse capabilities in terms of public priorities is, I have argued, an asset, forcing us to make clear what the value judgments are in a field where value judgments cannot be - and should not be avoided [...] The work of public valuation cannot be replaced by some cunningly clever assumption." [71] (p.110)
The argument that Sen makes is for how democracy, as a capability, contributes to an ongoing dialogue, allowing a constant reorganization of priorities involving all levels of governance, rather than strictly thought out and imposed top-down. Development and aid theorist William Easterly, in his influential book "The White Man's Burden" [20], explains how the poorest, which are often the ones targeted by aid and development interventions, are not engaged in this valuation process. Easterly argues that top-down aid and development goals are essentially anti-democratic, since the ones at the bottom do not dispose of any feedback or accountability mechanisms to change priorities at the top, such as voting or effective lobbying.

We do not have a solution for tackling the complexity and breadth of aid, development, or more specifically, ICTD initiatives with regards to their democratic framing and accountability. We argue that, within ICTD, the downplaying of playful engagements, which are, as we saw, prominent, and have the characteristics of freedom and voluntariness, harms communication and acknowledgment of people's desires and value judgments, and, as a consequence, increase communication problems within the different layers of ICTD work. We will now look at how these problems have emerged, and have started being discussed within ICTD, as well as implications for the evaluation of ICTD projects and dynamics more broadly.

\section{ICTD and play as failure}

In what is one of the first pieces in ICTD to reflect on these aspects, Ratan and Bailur provide us with examples of ICTD projects, which were classified as failures, despite, on a closer look, having brought significant value to people's lives. One such project is a community radio and telecentre known as OurVoices, an UNESCO funded initiative which installed a significant amount of ICTs in a village called Bhairavi for the purpose of disseminating what was considered "relevant information", and to examine ICT's impact on reducing poverty and enhancing development. While initially branded a success in improving different metrics from women's health to job creation, it quickly fell under scrutiny:

"We were told by the villagers that the radio set medium had been phased out soon after implementation (one of the reasons given was that the villagers started taking the radios out to their fields and listened to FM radio instead of OurVoices). During research listeners dismantled one of the radio loudspeakers in protest and used it to accompany the procession of the statue for a religious festival. The $N G O$ 's reaction to this was that the people were ignorant and uninterested in their own "development". They removed all the cabling, and set up the loudspeaker in another village" [64]

The authors proceed to detail a number of consequences that ensued from this situation and causing significant distress to the local population. Ratan and Bailur discus yet 
another project, Hole in the Office (HiO), which dealt with the introduction of PCs in a community, to aid with job searching [60]. Discontinuation of $\mathrm{HiO}$ occurred after it was determined that it was being used 25 times more for entertainment and games than for its intended function, thus satisfying no development goal:

"Yet, across the board the perception was that the PC was a "good" thing and that free access should not be discontinued" [64].

What these examples tell us is what Sey and Ortoleva have called "negative perceptions" of play within ICTD [75]. These perceptions lead to situations in which behaviors, that are not intended to occur around the specific ICTD intervention, are dismissed or censored even if they are highly valued by the communities. This has implications for people's agency, defined by Sen:

"I am using the term 'agent' [...] as someone who acts and brings about change, and whose achievements can be judged in terms of her own values and objectives, whether or not we assess them in terms of some external criteria as well", [71].

This highlights tensions between communities and individual's values and goals, and external criteria for assessment, which, as we will now see, bears some damaging consequences for ICTD dynamics.

\section{Implications for evaluation}

The issue of downplaying the role of play within ICTD is not just one of overlooking community and individual agencies, as problematic as that is, but has implications for the evaluation of projects as well. Ramesh, the project manager of OurVoices explains why it is so hard to get an understanding of what is actually happening in ICTD projects such as OurVoices:

"It is hard to know if people are really listening. In a survey, if we ... ask whether they watch TV or listen to us, they say yes. [...] The minute they see us, they tell us what we want to hear. They say yes, yes we listened. They feel guilty for choosing entertainment over development, like something which is good for them." [64]

The tension between what "insiders" may legitimately desire and what they perceive "outsiders" want to hear has been documented in other places [16, 36, 55] and may at times prevent even a basic understanding of the situation. This has been documented in developing work [16, 55], and has been more generally known to be an already existing characteristic of trials [10], which should not be encouraged, if we want to elicit a rich understanding of the communities as well as the ICTD projects themselves. These concerns are echoed by Kuriyan and Toyama, remarking that "what rural villagers want and what we think they need are frequently different" [46].
This is an issue, which affects ICTD's understanding of ICT adoption dynamics and motivations. To illustrate this mismatch, Heeks discusses a survey conducted in Tanzania reporting that fewer than $15 \%$ of mobile owners believed that the benefits of owning mobiles justified the costs [56]. To this, Heeks asks: "Um . . . so if you believe that guys, why on earth do you own a mobile? " [34] Heeks is suggesting that a richer story is waiting to be told. A story that was not reported, either because there was no way to get at the rationale for the actual reasons leading people to make that investment, or because it is the kind of information that ICTD, with its narrower focus on pre-defined development goals, is in a way not always prepared to assimilate.

Ferreira and Höök have discussed these tensions in their work around mobile phone adoption in Rah Island, Vanuatu [24]. They focus on tensions not just between ICTD and the communities, but within the communities themselves, leading to obstacles in reporting and getting a deeper understanding as to people's motivations, and indeed rightful desires, to acquire and engage with modern ICTs. These tensions should not be fed within ICTD dynamics, if we want an honest engagement with the recipients of these development projects, and an understanding as to what motivates the spending of significant amounts of resources in acquiring these, as Heeks explains:

"The significant amounts being spent by the poor on mobiles indicate that phones have a significant value to the poor [...] we [the ICTD community] have long known [...] that 'poverty' is not just about money and, hence, that poverty interventions and tools can usefully target more than just financial benefits" [34]

This tension between perceived value and the financial efforts made by the poor to acquire these technologies is present in other settings, as pointed out by Song, where according to him people can spend more than $50 \%$ of their income on personal access to ICTs despite this representing an effort some would consider excessive [79]. The question is whether it is reasonable to simply assume irrationality in such behaviors, and subsequently risking censoring them, or whether there is something to learn from these uses.

If we believe the latter to be the case, then we need to address the dynamics that exist within ICTD, and development work at large, between funding agencies, practitioners and recipients, that are partly responsible for undermining the appreciation of these more complex and irreducible, yet entirely legitimate forms of engaging with technology.

\section{Summary}

Capabilities, according to Sen, should be:

"Deliberative in order to accommodated ongoing discussions regarding priorities and new information, rather than taking any predefined metric (seducing as it may be) as an ultimate indicator of well-being, poverty or freedom of different kinds" [71] 
If we are to return to Schwartz and colleague's recognition and acceptance of non-prescribed uses [70], we see how it not only helped achieve the project's goals, but also generated a more open and honest interaction between the different stakeholders. This in turn also helps avoid entirely undesirable feelings of guilt, as brought up by Ramesh from OurVoices, stemming from people using technology in other ways than their instructed use. These, in turn, may hide, what would otherwise be important aspects of technology use, which should be taken into consideration when trying to understand ICT usage and even, to some extent, explicitly catered to. The intentions and desires behind technology adoption, which often involves heavy financial sacrifices such as those Heeks [34] or Smyth and colleagues [77] have documented, remain underappreciated, given the failure to account for and respect people's legitimate desires. And this is the most important aspect to keep in mind: not only this tension affects ICTD goals by undermining the relationships between the different parties, but, on a more fundamental level, they are highly prescriptive of images that some ICTD projects entertain about their participants, as Ramesh explains:

"We might be giving a programme about an agricultural scheme, which the government might have for him, which might significantly increase his yield, but he's not interested in listening to it, because it's boring. You know, he wants to watch the movie. That's the competition we've got, the challenge we have to overcome." [64]

As a final note, the constructive role of play is, in a way, instrumental, since we frame it as a means towards achieving other goals (such as better evaluation and feedback loops). But because it can be a broad means towards negotiating the goals and values of development themselves, rather than achieving them directly, it is important to, as Sen does, view this role under a different light, more tied to the idea of freedom itself, rather than a narrower conception of social and economic progress.

\section{PLAY AS CONSTITUTIVE}

We have devoted some time here to explain the importance of play from an instrumental and constructive viewpoints, partly in order to alleviate some concerns that may stem from an often - and wrongly - assumed contradiction between the triviality of play and the seriousness of other goals, such as development ones. Our main point in this work however, and what we will argue now in more detail, is that play is intrinsically important: its constitutive role as an integral part of the human experience. This is regardless of whether or not it helps achieve other goals, such as the ones discussed above.

We have seen how most academic thought overwhelmingly speaks of play as a fundamental and innate aspect of life. From Huizinga's initial framing of play, as the basis from which culture emerges [40], to Nussbaum's classification of play as a basic capability in humans [59]. Arguably the field where this has been most emphasized is within psychology where from Piaget's early work [61], the importance to stimulate and encourage play amongst children is an uncontroversial topic within the field. More recently psychologist Peter Gray has published extensive work on the topic, summing up the views of most cognitive psychology on the issue, arguing that, play is not only fundamental, and an important tool for learning, but also something to be unleashed [31]. The Convention on the Rights of the Child has long stated in its article 31: "States Parties recognize the right of the child to rest and leisure, to engage in play and recreational activities appropriate to the age of the child and to participate freely in cultural life and the arts." [4]. While acknowledging the right of play for children is undoubtedly an important step, even if it is far from being a reality throughout the globe, it should not detract from the fact that play is important regardless of age.

\section{The desire to play}

We have seen an emergence of a, yet sparse, body of work which has began documenting playful behaviors around technology in ICTD. We have seen how South African mobile users have appropriated MXit, an instant messaging system, for the purposes of gaming [83], and other examples abound of such appropriations within the developing world $[15,75,77]$. Social networks and interpersonal communication have also been source of enthusiasm [70, 83, 86]. Larger surveys show users in the developing world engaging with gaming in internet cafes and other points of access $[45,74]$, and more generally many have discussed the significant amounts of resources that users, even within resource constrained situations, are willing to place in entertainment and gaming $[26,34,63]$.

This desire for play, entertainment and personal uses in the developing world should not be striking, as this accounts for a significant portion of technological use outside the developing world as well. It is up to ICTD to acknowledge and study what people do, and want to do with technology, rather than ascribing a priori intentions. Here HCI can provide some guidance, where studies have emerged of technology use, studied and understood, beyond instrumental framings, and rather as an appreciation of legitimate technology use: for instance Juhlin and Weilenmann's work on hunting [41] or Jeffrey and Shaowen Bardzell's work on sex toys [6]. Both of these focus on the activities themselves, helping support the growing interest in those domains. However, we also find also some obscurity around these issues in HCI as well, as Genevieve Bell pointed out in her keynote at CHI 2010 [7]. Some similar resistances exist in appreciating activities for their own sake, with activities such as sports, sex or religion remaining largely underrepresented in research in comparison to their prominence within actual ICT use.

We have seen how play occurs even around the simplest digital interactions [24], and how people engage in extensive work to creatively appropriate technologies for their 
own desired uses, regardless of how limited the opportunities for play seem to be. But we argue that people should not have to work so hard to derive pleasure and other value from technologies which many of us take for granted, and that we should complement and assist, rather than resist, the motivations and desires that many communities are already very visibly displaying around ICT adoption.

\section{Taking play seriously}

There are two further examples we would like to bring up as part of emphasizing the non-triviality of play (although the play activities may themselves be trivial). In severely resource-constrained situations, play does not become a luxury one cannot afford. In many, rather severe, cases play becomes all the more important as a means to escape current hardships, particularly through the aspects of escape and order that play brings to life. It is in this way we would like to discuss these two important examples. The first comes from the Great Depression era, in the United States, where a growth in resources allocated to leisurely activities grew, rather than diminish, during the period between 1890 and 1940 [25], across socio-economic backgrounds.

The second, and one of the most striking examples of this is given to us by George Eisen in "Children and Play in the Holocaust", where Eisen tries to reconcile, and come to terms with, the horror of the situation and the importance of play among children [21]. In his work it is clear how easily one may completely ignore the importance and role of play in those situations. Eisen describes play as it occurred, dissecting its role within that context, without underappreciating or downgrading the urgency and deep precariousness of the situations those children found themselves in. It was, according to Eisen, precisely play, which allowed children to preserve a level of humanity throughout their plight.

While tensions around the appreciation of play may appear particularly acute in ICTD settings, they have resonances in different moral tales present in the Western world as well. From Aesop's fable of the grasshopper and the ant [14], in which the grasshopper finds its demise, after spending all summer singing and not preparing adequately for winter, while the ant thrives in its dutifulness (Suits dedicates a whole book defending the grasshopper's lifestyle as the only way to lead a good life [81]), to for instance ideas about work ethics as a trait of cultures or religions (such as Max Weber's treatise on protestant work ethics [84]). Within popular and academic thought, multiple traditions exist that reinforce these strict prioritizations between activities, most famously embodied by Mazlow's pyramid of needs.

These, and other, moral tales shape the way we conceive of play, work, dutifulness and so on, and are likely to permeate ICTD and academic work. However, we need to question these assumptions by showing how notions of play and work, for instance, are not contradictory. We are often better served appreciating the ways in which people choose to adopt ICTs, regardless of their socio-economic situation, than perpetuating play's relative obscurity within ICTD work. A failure to understand motivations behind ICT use is likely to result in a failure to provide real benefits to those we target through our studies and interventions.

\section{DISCUSSION}

We have discussed the importance of looking at play as a capability within ICTD work, and analyzed its instrumental, constructive and constitutive roles, positioning relevant work according to this framework. In order to help alleviate some of the issues around the acknowledgment of play within ICTD, we propose some broader topics for discussion: (1) the dynamics of paternalism and a priori prescription of goals existing in ICTD, (2) how play has a narrative and rhetoric role within ICTD, and development more generally, which influences the way it is discussed, prioritized or accepted. We end by (3) discussing how this is not just an issue of designing, or deploying, playful technologies in ICTD, but rather a broader discussion that needs to take place in order to reform the term of play as, essentially, a quality of life and freedom issue.

\section{Paternalism and prescription}

Many have denounced the paternalistic dynamics that occur within development work $[15,32,64]$. Anthropologists like Arturo Escobar have discussed the making of concepts like "development" and "third" world, as narrow conceptions of the people described, as passive receivers of external knowledge which is good for them [23]. Manzo and colleagues discuss these dymanics: "What political economy wanted, in short, was to take the poor, inefficient Third World decision maker by the hand, lead him to the development candy store, and show him how to get the best buy for his meager pennies." [50]. Ratan and Bailur also discuss this, through their recounting of Helena Norberg-Hodge's [36] ethnographic fieldwork and her experience of coming back to Ladakh, India ten years after having been told by a local that there was no existing poverty in that location, only to find that same person begging tourists for help and emphasizing her situation of poverty .

What is at stake here is not just the dynamics that are created between the recipients of aid, donors and development practitioners, but more broadly the construction of these settings, as Escobar argues [23]. The interactions that development work generate can yield possibly detrimental dynamics between recipients of development work, funding organizations and development practitioners, and as Smyth and colleagues write, we must question:

"Are needs really more urgent than desires? Who defines which is which? Do researchers exaggerate the urgency of 'needs' due to their own biases and preconceptions?" [77]

Perhaps here we can learn from a deeper understanding of local needs and aspirations to inform the nature of ICTD interventions. To gain this deeper understanding, we may 
borrow even more from traditions of anthropology and sociology, as suggested by Burrell \& Toyama [12]. This may allows us to step away from some of the more top-down, pre-defined metrics (as suggested by Burrel \& Toyama [12], Heeks [33] and Van Dijk [18], to name a few). But this is not only a discussion between top down vs. bottom up approaches for development, as embodied most notably by Jeffrey Sachs [68] and William Easterly [20]. Both of these approaches have their own benefits and limitations. The important aspect to keep in mind is that, to be effective, both will require constant loops of feedback and accountability to avoid reinforcing some of these representational and paternalistic dynamics.

Feelings of shame or guilt, such as those brought up by Ramesh from OurVoices, further marginalize the understanding of these practices and undermine the informational base on which ICTD work is conducted, i.e. the capacity to understand what the values and needs are for the users. Insights on steering clear from paternalistic modes of development thinking are not necessarily a novelty introduced in this work. But we argue that the acknowledgment of play, as a legitimate activity valued regardless of socio-economic situation, challenging us to observe and respect these behaviors, can be a key element to help unlock some of the vices that development work can generate.

\section{Play as a narrative/rhetoric device}

We have defined play according to a series of criteria that are not all necessary to classify something as play or not. It is rather a matter of family resemblances [85] between different activities which we reasonably qualify under play, rather than a perfectly defined concept. The ways in which we choose to frame and acknowledge certain activities as play, or not, has important repercussions. One repercussion might be that donors are unwilling to fund technologies for entertainment if that is how they are framed rather than to achieve socio-economic outcomes for instance. As project manger Ramesh (from the OurVoices project) mentions when queried as to the discrepancies between the intended goals of the project, people less than serious activities and the difficulty at getting at these:

"We can either approach community radio as what the community wants. If you make it that way, it will be music only. But at [the donor agency] we can't justify all this equipment to play music all day. There has to be a development angle." [64]

The implications of framing something as important or urgent can result in different levels of attention paid, and funding awarded, to different projects and communities. Smyth and colleagues ask:

"Do researchers exaggerate the urgency of 'needs' due to their own biases and preconceptions?” [77]

While certainly biases and preconceptions from researchers play a part in how projects are conducted and evaluated, researchers are only a part of the structures that determine and conduct development and ICTD work. The same concerns of justifying technology use that Ramesh, from OurVoices, brought up, may not be so dissimilar to the ways in which ICTD practitioners and researchers must justify their own work, as Adam Smith famously remarked:

"The interest of the dealers, however, in any particular branch of trade or manufactures, is always in some respects different from, and even opposite to, that of the public." [76]

This is not intended to ascribe malice or ill intentions onto ICTD institutions, researchers, practitioners and other parties involved, from whom we assume an a priori deep commitment to their work. This is rather a reminder that dynamics which emerge from these institutional arrangements may at times ignore those with less voice to lobby for their interests, as Easterly discusses [20]. By not acknowledging playful behaviors around technology we may be engaging in a poor representation of people, and as a consequence, assuming priorities without deliberation. This may appear particularly prominent in development work, where the main focus is on a stricter view of socioeconomic needs, as already established in the MDG.

These are part of larger structures and dynamics, which can be difficult to escape. These are engrained, as we saw in academic thought, religious morals, theories around work ethics and even in children's fables. Play can mean different things, few of which deserve the ill treatment and depreciation that it often gets. We suggest a repurposing of the concept of play at all levels, to acknowledge these fundamental human forms of engagement, enriching academic thought more generally, and ICTD interventions more specifically.

\section{Not (just) a design issue but a larger debate}

There are certainly better and worse ways to design play experiences with and around digital technologies, such lessons appear more prominently within game studies [69]. One important issue outside the gaming world, and which has inspired play thinking in HCI is Sengers' and Gaver's proposition for open interpretation [73] and Höök's proposition for designing open surfaces [38], as a way to allow for a freer engagement with technology.

Within an ICTD context, some such as ourselves have suggested looking at HCI, as a more mature, design oriented, discipline aimed at understanding people and technology, for design recommendations for play in ICTD, such as openness $[15,51]$. While this certainly has some value, it is also important to remember that many play experiences, like games, are often extensively and carefully crafted to provide enhanced experiences of their own. In that sense openness is not a panacea to play, and both kinds of design strategies have a place when providing people with interesting and engaging playful experiences. 
Regardless of strategy, design alone can hardly challenge the existing institutional, moral and ethical structures, discussed earlier, that obfuscate play activities. These contribute to a perception, as Sutton-Smith describes, of other activities, as being "wiser" [82]. The work that must be done, is not just the technical work of designing these experiences, as important as that is, but a questioning of priorities and a constant renegotiating of these priorities with the people who are supposed to benefit from these technologies. It involves an ongoing dialogue, while steering away from a priori moral imperatives, which do not even seem to match with the ways in which people value digital technologies, both within ICTD contexts and at large.

Openness in designing systems can certainly be one of the mechanisms, amongst other ways of crafting and designing for play, with which to provide positive and desirable experiences with digital technologies. But we argue that openness as a value may be more important in crafting the ICTD projects and interventions themselves rather than the specific technologies, so that these can accommodate new insights, encouraging mutual deliberation and learning [47].

By resisting a priori goals, shifting the value of the term play and focusing more broadly on the interventions, rather than mainly on the systems' designs, we hope to help alleviate some of the tensions around this topic, thinking more broadly about ICTD work and involving those who the work will affect, in more open deliberations over goals and priorities. Play is as an important capability to enhance, it should not be a source of guilt, but rather representing a large portion of what we value in technology and life.

\section{CONCLUSION}

We have seen how play, as a capability, helps us appreciate its different roles (instrumental, constructive and constitutive), showing how there is no inherent conflict between play and development, and how the acknowledgment of play is fundamental for a more honest and rigorous engagement with ICTD work. A dialogue around play will always exist within societies and academia, setting rules and deliberating over its appropriateness, this deliberation process should be encouraged, not restricted. But most importantly, this framing allows us to place the focus on its constitutive aspect, valuing play regardless of other development goals - in the same way we should ensure gender equal opportunities and democratic rights despite any other social and economic rationale, as essential freedoms, allowing people to deliberate on, and live, their lives in the ways they have reason to value and see fit - unapologetically focusing on a better quality of life.

\section{REFERENCES}

[1] Anand, S. and Sen, A. 1994. Human Development Index: methodology and measurement. Human Development Report Office (HDRO), United Nations Development Programme (UNDP).
[2] Apter, M.J. 1989. Reversal theory: motivation, emotion, and personality. Routledge.

[3] Arora, P. 2012. The leisure divide: can the "Third World"come out to play? Information Development. 28, 2 (2012), 93-101.

[4] Assembly, U.G. 1989. Convention on the Rights of the Child. United Nations, Treaty Series. 1577, 3 (1989).

[5] Banerjee, A. et al. 2005. Remedying education: Evidence from two randomized experiments in India. National Bureau of Economic Research.

[6] Bardzell, J. and Bardzell, S. 2011. Pleasure is your birthright: digitally enabled designer sex toys as a case of third-wave HCI. Proceedings of the 2011 annual conference on Human factors in computing systems (New York, NY, USA, 2011), 257-266.

[7] Bell, G. 2010. Messy Futures: culture, technology and research.

[8] Bødker, S. 2006. When second wave HCI meets third wave challenges. NordiCHI '06: Proceedings of the 4th Nordic conference on Human-computer interaction (New York, NY, USA, 2006), 1-8.

[9] Boyd, D.F. and Krasnow, H.S. 1963. Economic Evaluation of Management Information Systems. IBM Syst. J. 2, 1 (Mar. 1963), 2-23.

[10] Brown, B. et al. 2011. Into the wild: challenges and opportunities for field trial methods. Proceedings of the SIGCHI Conference on Human Factors in Computing Systems (2011), 1657-1666.

[11] Brown, S. and Vaughan, C. 2010. Play: How It Shapes the Brain, Opens the Imagination, and Invigorates the Soul. Scribe Publications.

[12] Burrell, J. and Toyama, K. 2009. What constitutes good ICTD research? Information Technologies \& International Development. 5, 3 (2009), pp-82.

[13] Caillois, R. 1961. Man, play, and games. University of Illinois Press.

[14] Calder, A. 2001. The Fables of La Fontaine: Wisdom brought down to earth. Librairie Droz.

[15] Chirumamilla, P. and Pal, J. 2013. Play and power: a ludic design proposal for ICTD. Proceedings of the Sixth International Conference on Information and Communication Technologies and Development: Full Papers-Volume 1 (2013), 25-33.

[16] Crewe, E. and Harrison, E. 1998. Whose development. An ethnography of aid. (1998), 23-65.

[17] Csíkszentmihályi, M. 2008. Flow: The Psychology of Optimal Experience. HarperCollins.

[18] Van Dijk, J.A. 2006. Digital divide research, achievements and shortcomings. Poetics. 34, 4 (2006), 221-235.

[19] Donner, J. 2009. Blurring livelihoods and lives: The social uses of mobile phones and socioeconomic development. innovations. 4, 1 (2009), 91-101.

[20] Easterly, W.R. 2006. The White Man's Burden: Why the West's Efforts to Aid the Rest Have Done so Much Ill and so Little Good. Penguin Press. 
[21] Eisen, G. 1990. Children and play in the Holocaust: Games among the shadows. Univ of Massachusetts Press.

[22] Ellwood-Clayton, B. 2006. All we need is love-and a mobile phone: Texting in the Philippines. Cultural Space and Public Sphere in Asia, Seoul, Korea. (2006).

[23] Escobar, A. 2011. Encountering development: The making and unmaking of the Third World. Princeton University Press.

[24] Ferreira, P. and Höök, K. 2012. Appreciating pleiplei around mobiles: Playfulness in Rah Island. Proceedings of the 2012 annual conference on Human factors in computing systems (New York, NY, USA, 2012).

[25] Fischer, C.S. 1994. Changes in leisure activities, 1890-1940. Journal of Social History. (1994), 453475.

[26] Galarneau, L. 2014. Global Gaming Stats: Who's Playing What, and Why. Big Fish Games. (2014), 15.

[27] Gallagher, C.A. 1974. Perceptions of the value of a management information system. Academy of Management Journal. 17, 1 (1974), 46-55.

[28] Gaver, W.W. et al. 2004. The drift table: designing for ludic engagement. $\mathrm{CHI}$ '04 extended abstracts on Human factors in computing systems (New York, NY, USA, 2004), 885-900.

[29] Gee, J.P. 2003. What video games have to teach us about learning and literacy. Computers in Entertainment (CIE). 1, 1 (2003), 20-20.

[30] Geertz, C. 1991. Deep Play. Rethinking Popular Culture: Contemporary Perspectives in Cultural Studies. (1991), 239.

[31] Gray, P. 2013. Free to learn: Why unleashing the instinct to play will make our children happier, more self-reliant, and better students for life. Basic Books.

[32] Gumucio-Dagron, A. 2001. Making waves: Stories of participatory communication for social change. Rockefeller Foundation New York.

[33] Heeks, R. 2008. ICT4D 2.0: The Next Phase of Applying ICT for International Development. Computer. 41, 6 (2008), 26-33.

[34] Heeks, R. 2008. Mobiles for Impoverishment? ICTs For Development.

[35] Henricks, T.S. 2006. Play reconsidered: Sociological perspectives on human expression. University of Illinois Press.

[36] Hodge, H.N. 2013. Ancient futures: learning from Ladakh. Random House.

[37] Hole-in-the-Wall: 2011. http://www.hole-in-thewall.com/insight.html. Accessed: 2015-01-24.

[38] Höök, K. 2006. Designing familiar open surfaces. Proceedings of the 4th Nordic conference on Humancomputer interaction: changing roles (New York, NY, USA, 2006), 242-251.
[39] Horst, H.A. and Miller, D. 2006. The cell phone: an anthropology of communication. Berg.

[40] Huizinga, J. 1939. Homo Ludens: A Study of the Play-Element in Culture. Routledge.

[41] Juhlin, O. and Weilenmann, A. 2008. Hunting for fun: solitude and attentiveness in collaboration. Proceedings of the 2008 ACM conference on Computer supported cooperative work (New York, NY, USA, 2008), 57-66.

[42] Kam, M. et al. 2008. Designing e-learning games for rural children in India: a format for balancing learning with fun. Proceedings of the 7th ACM conference on Designing interactive systems (2008), 58-67.

[43] Kam, M. et al. 2009. Improving literacy in rural India: Cellphone games in an after-school program. Information and Communication Technologies and Development (ICTD), 2009 International Conference on (2009), 139-149.

[44] Kaprow, A. 2003. Essays on the Blurring of Art and Life. Univ of California Press.

[45] Kolko, B. et al. 2014. The value of non-instrumental computer use: Skills acquisition, self-confidence, and community-based technology training. TASCHA.

[46] Kuriyan, R. et al. 2008. Information and communication technologies for development: The bottom of the pyramid model in practice. The Information Society. 24, 2 (2008), 93-104.

[47] Loudon, M. and Rivett, U. 2014. Enacting Openness in ICT4D Research. Open Development: Networked Innovations in International Development. (2014), 53.

[48] Lucas, H.C. 1973. User reactions and the management of information services. Management Informatics. 2, 4 (1973), 165-172.

[49] Malaby, T.M. 2007. Beyond play a new approach to games. Games and culture. 2, 2 (2007), 95-113.

[50] Manzo, K. 1991. Modernist discourse and the crisis of development theory. Studies in comparative international development. 26, 2 (1991), 3-36.

[51] Marsden, G. 2009. UNDER DEVELOPMENT Electronic tablecloths and the developing world. Looking ahead. 16, 2 (2009).

[52] Michael, D.R. and Chen, S.L. 2005. Serious games: Games that educate, train, and inform. Muska \& Lipman/Premier-Trade.

[53] Mitra, S. et al. 2005. Acquisition of computing literacy on shared public computers: Children and the" hole in the wall." Australasian Journal of Educational Technology. 21, 3 (2005), 407.

[54] Mitra, S. 2003. Minimally invasive education: a progress report on the "hole-in-the-wall" experiments. British Journal of Educational Technology. 34, 3 (2003), 367-371.

[55] Mosse, D. 2001. People's knowledge', participation and patronage: Operations and representations in rural development. Participation: The new tyranny. (2001), 16-35. 
[56] Mpogole, H. et al. 2008. Mobile Phones and Poverty Alleviation: A Survey Study in Rural Tanzania. Proceedings of 1st International Conference on M4D Mobile Communication Technology for Development (Karlstad University, Sweden, 2008), 69-79.

[57] Nussbaum, M. 2000. Women's capabilities and social justice. Journal of Human Development. 1, 2 (2000), 219-247.

[58] Nussbaum, M.C. 2011. Creating capabilities. Harvard University Press.

[59] Nussbaum, M.C. et al. 1993. The quality of life. Clarendon Press Oxford.

[60] Pawar, U.S. et al. 2008. An „Office Hole-in-theWall" Exploration. Microsoft Research Technical Report.

[61] Piaget, J. and Cook, M.T. 1952. The origins of intelligence in children. (1952).

[62] Poverty, E. 2015. Millennium development goals. United Nations. Available online: http://www. un. org/millenniumgoals/(accessed on 23 August 2011). (2015).

[63] Radha, G. 2013. Mobile Gaming in Emerging Markets - Some Insights. TreSensa.

[64] Ratan, A.L. and Bailur, S. 2007. Welfare, agency and "ICT for Development." Proceedings of the International Conference on Information and Communication Technologies and Development (Bangalore, 2007).

[65] Raza, A.A. et al. 2013. Job opportunities through entertainment: Virally spread speech-based services for low-literate users. Proceedings of the SIGCHI Conference on Human Factors in Computing Systems (2013), 2803-2812.

[66] Raza, A.A. et al. 2012. Viral entertainment as a vehicle for disseminating speech-based services to lowliterate users. Proceedings of the Fifth International Conference on Information and Communication Technologies and Development (2012), 350-359.

[67] Riezler, K. 1941. Play and Seriousness. The Journal of Philosophy. 38, 19 (1941), 505-517.

[68] Sachs, J. 2005. The End of Poverty: Economic Possibilities for Our Time. Penguin Press.

[69] Salen, K. and Zimmerman, E. 2004. Rules of play: game design fundamentals. MIT Press.

[70] Schwartz, A. et al. 2013. Balancing burden and benefit: non-prescribed use of employer-issued mobile devices. Proceedings of the Sixth International Conference on Information and Communications Tech- nologies and Development: Notes-Volume 2 (2013), 140-143.

[71] Sen, A. 1999. Development as freedom. Oxford University Press.

[72] Sen, A. and others 1993. Capability and well-being. na.

[73] Sengers, P. and Gaver, B. 2006. Staying open to interpretation: engaging multiple meanings in design and evaluation. Proceedings of the 6th conference on Designing Interactive systems (2006), 99-108.

[74] Sey, A. et al. 2013. Connecting people for development: Why public access ICTs matter (eBook). (2013).

[75] Sey, A. and Ortoleva, P. 2014. All Work and No Play? Judging the Uses of Mobile Phones in Developing Countries. Information Technologies \& International Development. 10, 3 (2014), pp-1.

[76] Smith, A. and Nicholson, J.S. 1887. An Inquiry Into the Nature and Causes of the Wealth of Nations... T. Nelson and Sons.

[77] Smyth, T.N. et al. 2010. Where there's a will there's a way: mobile media sharing in urban india. Proceedings of the 28th international conference on Human factors in computing systems (New York, NY, USA, 2010), 753-762.

[78] Solow, R.M. 1987. We'd better watch out. New York Times Book Review. 36, (1987).

[79] Song, S. 2009. Nathan and the Mobile Operators. Many Possibilities.

[80] Statistics, I.T.U. 2014. International Telecommunication Union. ITU ICT Statistics. Retrieved February.

[81] Suits, B. 1978. The grasshopper: Games, life and utopia. Broadview Press.

[82] Sutton-Smith, B. 2009. The ambiguity of play. Harvard University Press.

[83] Walton, M. and Pallitt, N. 2012. "Grand Theft South Africa": games, literacy and inequality in consumer childhoods. Language and Education. 26, 4 (2012), 347-361.

[84] Weber, M. 1905. The Protestant Ethic and the Spirit of Capitalism: and other writings. Penguin.

[85] Wittgenstein, L. 1953. Philosophical investigations. John Wiley \& Sons.

[86] Wyche, S.P. et al. 2013. Facebook is a luxury: An exploratory study of social media use in rural Kenya. Proceedings of the 2013 conference on Computer supported cooperative work (2013), 33-44. 